\title{
Pseudotumour cerebri and the Turner syndrome
}

\author{
VIRGINIA P SYBERT, ${ }^{*}$ THOMAS D BIRD, $†$ DARRELL J SALK $\ddagger$
}

From the Departments of Medicine and Pediatrics, ${ }^{*}$ University of Washington Medical School and Children's Orthopedic Hospital and Medical Center, Department of Medicine $\dagger$ University of Washington Medical School and Veteran's Administration Hospital and Departments of Pathology and Pediatrics $\ddagger$ University of Washington Medical School and Children's Orthopedic Hospital and Medical Center, Seattle, Washington USA

SUMMARY One of 170 patients with karyotype-proven Turner syndrome from our institution has had pseudotumour cerebri. This patient and one previous report suggest that patients with Turner syndrome may be predisposed to increased intracranial pressure. Fourteen patients with pseudotumour cerebri were ascertained from hospital records; karyotypes of four were obtained and were normal. Karyotyping may be appropriate in women with pseudotumour cerebri who also have infertility, short stature, multiple pregnancy losses, or other features suggestive of Turner syndrome.

Pseudotumour cerebri (benign intracranial hypertension) has been reported' in a woman with Turner syndrome (gonadal dysgenesis with $\mathrm{X}$ chromosome abnormality) who was mosaic for a cell line containing only one $\mathrm{X}$ chromosome and a cell line containing a normal $X$ and an isochromosome for the long arm of $X: 45, X / 46, X, i(X q)$. One of our patients with Turner syndrome and an unusual karyotype also developed pseudotumour cerebri. We question whether the two disorders might be causally related.

\section{Case report}

RS was a mildly mentally retarded girl who presented at age 8 years with complaints of headache. Her neurological examination was normal with the exception of papilloedema. A ventricular tap was performed and the opening pressure was in excess of $300 \mathrm{~mm} \mathrm{H}_{2} \mathrm{O}$; the ventriculogram was normal. Her symptoms and signs responded promptly to dexamethasone. Corticosteroid therapy was gradually discontinued and over the next several years occasional recurrent symptoms of headache and incoordination were treated by repeated lumbar punctures, which revealed opening pressure in the range of $300 \mathrm{~mm} \mathrm{H}_{2} \mathrm{O}$. By the age of 12 years, her lumbar cerebrospinal fluid opening pressure was down to $180 \mathrm{~mm} \mathrm{H}_{2} \mathrm{O}$.

Address for reprint requests: Dr Virginia P Sybert, Division of Medical Genetics, Children's Orthopedic Hospital and Medical Center, 4800 Sand Point Way N.E., Box C-5371, Seattle, Washington 98105, USA.

Received 7 February 1984 and in revised form 5 June 1984. Accepted 14 July 1984
At age eleven, short stature prompted evaluation and buccal smear was obtained. Twenty per cent of the cell\$ were positive for Barr bodies compared with $25 \%$ in thछ control, and the test was interpreted as normal for a female. Unbanded chromosomes from peripheral blood lymphocytes were studied when she was 13 years old. $O$ 35 cells examined, 30 were missing a $\mathbf{C}$-group chromosome and a diagnosis of $45, X / 46, X X$ mosaicism was made. She was then begun on oxandrolone to promote growth and visual disturbances, headache, and papilloedema recurred. The drug was stopped. Hypothyroidism was diagnosed at age 15 years and she was begun on Synthroid (levothyroxine sodium, USP). She had had spontaneous breast development and after thyroid therapy was instituted, she had spontaneous menses. Although she continued to menstrate monthly, LH and FSH were elevated. At 17, she developed severe menorrhagia. A course of Norlutate (norethindrone acetate) resulted in a recurrence of increased intracranial pressure with an opening lumbar cerebrospinal fluid pressure of over $400 \mathrm{~mm} \mathrm{H}_{2} \mathrm{O}$ and a partial hysterectomy was performed for uncontrollable menorrhagia.

At surgery, multiple tissues were obtained for chromosome analysis, including skin, ovaries, fallopian tubes and uterus (table). R-banding revealed that in those metaphases with 46 chromosomes there was a marker chromosome with the long arm of an $\mathrm{X}$ and an unidentifiable short arm of dark R-banding material. BudR labelling studies were performed using both cultures derived from the ovaries. The long arm of the marker chromosome was late replicating, suggesting that it was the inactivated $X$ 을 chromosome. The short arm material, however, appeared not to be late replicating, suggesting derivation from an 0 unidentified autosome. Thus, the patient was mosaic for $N$ 
Table $R$-banded cytogenetic analysis of multiple tissues from $R S$. Fifty cells were analysed from each tissue

\begin{tabular}{llc}
\hline Tissue & \multicolumn{2}{c}{ Percent of cells with karyotype } \\
\cline { 2 - 3 } & $45, X$ & $46, X$, rea $(X p)$ \\
\hline Skin & 14 & 86 \\
Uterus & 32 & 68 \\
Fallopian tube (left) & 12 & 88 \\
Fallopian tube (right) & 22 & 78 \\
Ovary (left) & 0 & 100 \\
Ovary (right) & 0 & 100 \\
\hline
\end{tabular}

monosomy $\mathrm{X}$ and for a cell line containing a normal $\mathrm{X}$ and a marker chromosome with the long arm of an $X$ and an unidentified segment of an autosome as the short arm: $45, X / 46, X$,rea(Xp). The parents of $R S$ had normal peripheral blood lymphocyte karyotypes.

Subsequent to the surgery FSH and LH were within the normal range, without any exogenous hormone replacement. She had had no recurrences of her papilloedema by age $181 / 2$ years, when she was lost to follow-up. At that time, she was still markedly obese, her height was $142.6 \mathrm{~cm}$ $(<3 \mathrm{rd} \%)$ and her weight was $54 \cdot 5 \mathrm{~kg}(25-50$ th \%).

\section{Materials and methods}

We first reviewed the medical records of our clinic population of 170 patients with Turner syndrome who had documented abnormal karyotypes. Patients ranged in age from 3 months to 78 years with a mean age of 26 years. Medical records of University Hospital for years 19651982 were reviewed for the diagnosis of pseudotumour cerebri in females. This diagnosis was confirmed in fourteen women. These patients had had headache, papilloedema and elevated cerebrospinal fluid pressure with no underlying recognisable cause after thorough evaluation.

Peripheral blood lymphocytes were cultured and harvested for analysis using standard techniques. Cultures of fibroblast-like cells were established in Leighton tubes from tissue explants and were maintained in Eagle's minimal essential medium (Grand Island Biological Co) supplemented with penicillin (100 units $/ \mathrm{ml})$ and $16 \%$ fetal bovine serum. Fibroblast cultures were harvested for karyotyping by standard suspension or in situ techniques. ${ }^{2}$ Chromosomes were analysed using standard Giemsa staining or GTG- or RHG-banding. Replication studies in cultured fibroblasts were performed by adding bromodeoxyuridine $\left(10^{-4} \mathrm{M}\right) 7$ hours prior to harvest (including one hour of colcemide arrest) using an RBG banding technique. ${ }^{3}$

\section{Results}

Among our 170 clinic patients with Turner syndrome, only one patient (RS) had had documented pseudotumour cerebri. Review of the medical records found no other patient with Turner syndrome with complaints of severe headache or papilloedema. The majority of the adult patients were being treated with oestrogen and progesterone in physiological doses.

Of the fourteen women ascertained from medical records with the diagnosis of pseudotumour cerebri, six could not be contacted, four refused karyotyping, and four had chromosome studies performed. None of the four patients had chromosomal evidence for Turner syndrome. All were obese.

\section{Discussion}

Pseudotumour cerebri is a disorder characterised by an idiopathic increase in intracranial pressure. ${ }^{4}$ It is associated with obesity and menstrual dysfunction and occurs more commonly in young females (M:F $=1: 2-1: 5)$. Numerous conditions have been associated with pseudotumour cerebri, including corticosteroid therapy, iron deficiency anaemia, hypervitaminosis $\mathrm{A}$, tetracycline and nitrofurantin therapy. ${ }^{4} \mathrm{~A}$ number of theories have been proffered for the physiological mechanisms underlying pseudotumour cerebri. Decreased cerebrospinal fluid absorption is the most generally accepted explanation. ${ }^{4}$ This may be induced by increased production of oestrones by adipocytes ${ }^{15}$ or other endocrine dysfunction. ${ }^{6}$

Women with Turner syndrome have gonadal dysgenesis and usually lack ovarian hormone production for which oestrogen and progesterone are taken in physiological replacement doses. They are short and are often obese. ${ }^{7}$ Therefore, women with Turner syndrome might be expected to be at increased risk for pseudotumour cerebri both because of perturbations in oestrogen/progesterone production and because of obesity. Some individuals with Turner syndrome will spontaneously feminise and/or are fertile; among these women, early menarche, spontaneous pregnancy loss, and chromosomally abnormal offspring are common, ${ }^{8}$ suggesting that even in this group of patients ovarian function is not normal.

Our single patient with pseudotumour cerebri and Turner syndrome was not receiving exogenous hormones at the time of the onset of the symptoms of increased intracranial pressure. She developed spontaneous menses and menorrhagia at age 14. Her pseudotumour cerebri did not recur at that time, nor at age 15 years when she was begun on thyroid replacement. It is not stated whether the other reported patient ${ }^{1}$ with Turner syndrome was receiving exogenous hormones at the time of her first episode of pseudotumour cerebri. She had had a total abdominal hysterectomy and bilateral salpingo-oophorectomy one year prior to the onset of her signs of increased intracranial pressure. She had not spontaneously feminised and had responded to a trial of oral contraceptives with withdrawal 
bleeding prior to her hysterectomy. She was obese with a height of $150 \mathrm{~cm}(<3 \mathrm{rd}$ percentile) and a weight of $73 \mathrm{~kg}$ (90th percentile).

If Turner syndrome and pseudotumour cerebri are causally linked, the latter should be seen with increased frequency in a Turner syndrome population. Only one of 170 Turner syndrome patients in our clinic had documented pseudotumour cerebri. Papilloedema, visual disturbances and severe headache were not reported in any of the other patients. However, spinal fluid pressures were not obtained, and there remains the possibility that there is an asymptomatic elevation of baseline cerebrospinal fluid pressure in Turner syndrome. We are unaware of any reports in the literature other than that of Donaldson and Binstock.'

Among the 14 women with pseudotumour cerebri, all were obese, two had onset of increased intracranial pressure during pregnancy, three had recurrent miscarriages, and four had menstrual irregularities and/or ovarian abnormalities. The number of patients with pseudotumour cerebri that we were able to karyotype is small; while it is possible that one or more of the unkaryotyped individuals has an $\mathrm{X}$ chromosome abnormality, this is unlikely. Five have had two or more normal pregnancies and no history of pregnancy loss. None of the unkaryotyped subjects for whom heights were available were less than $156 \mathrm{~cm}\left(5^{\prime} 1^{1 / 2} 2^{\prime \prime}\right)$ tall, again making it highly unlikely that they have Turner syndrome. ${ }^{9}$ The number of patients studied here may be too small to prove or disprove an association between the two disorders. Both pseudotumour cerebri and Turner syndrome are uncommon and a larger population base is needed to establish firmly or to exclude an association.

It is interesting to speculate that women with
Turner syndrome may be at increased risk for pseudotumour cerebri because of obesity and hormonal status, rather than because of a primary $\mathrm{X}$ chromosome abnormality. Our patient with both disorders had an atypical chromosome constitution as well as evidence for ovarian function. We suggest that the diagnosis of Turner syndrome should be considered and chromosome studies obtained in those women with pseudotumour cerebri who have had multiple pregnancy losses, early menopause, infertility or short stature, as these may be the only indicators of Turner syndrome. ${ }^{4}$

\section{References}

${ }^{1}$ Donaldson JO, Binstock ML. Pseudotumor cerebri in an obese woman with Turner syndrome. Neurology (NY) 1981;31:758-60.

${ }^{2}$ Schmid W. A technique for in situ karyotyping of primary amniotic fluid cell cultures. Humangenetik 1975;30:325-30.

${ }^{3}$ Korenberg JR, Freedlender EF. Giemsa technique for the detection of sister chromatid exchanges. Chromosoma 1974;48:355-60.

${ }^{4}$ Ahlskog JE, O'Neill BP. Pseudotumor Cerebri. Ann Int Med 1982;97:249-56.

${ }^{5}$ Donaldson JO. Pathogenesis of pseudotumor cereb syndromes. Neurology (NY) 1981;31:877-80.

- Von Dop CV, Conte FA, Koch TK. Pseudotumor cere bri associated with initiation of levo-thyroxine therap $T$ for juvenile hypothyroidism. New Engl $J$ Med 1983;308: 1076-80.

${ }^{7}$ Hall JG, Sybert VP, Williamson RA, et al. Turner's syn drome. West J Med 1982;137:32-4.

${ }^{8}$ Singh DN, Hara S, Foster HW, et al. Reproductive per? formance in women with sex chromosome mosaicism. Obstet Gynecol 1980;55:608-11.

${ }^{9}$ Sybert VP. Adult height in Turner syndrome with and without androgen therapy.J Pediatr 1984;104:365-9. 